\title{
ANALISIS KINERJA KARYAWAN BANK PANIN KCU KOTA SURAKARTA
}

\author{
Windy Helena, Sudarwati, Istiqomah \\ Program Studi Manajemen, Fakultas Ekonomi, Universitas Islam Batik Surakarta. \\ E-mail :windy.helena@gmail.com
}

\begin{abstract}
This study aims to determine whether there is an influence of organizational culture, work stress, and work rotation on employee performance. The population in this study were all employees of Bank Panin KCU Surakarta. The sampling technique uses purposive sampling method. Based on the purposive sampling method, a sample of 78 employees was obtained. Data analysis method used in this study is to use multiple linear regression analysis. Based on the results of simultaneous testing ( $F$ test) shows that the independent variables (organizational culture, work stress, and job rotation) have a positive and significant effect on the dependent variable (employee performance). Based on partial testing (t test) shows that organizational culture variables, work stress, and job rotation have a positive and significant effect on employee performance. Based on the coefficient of determination test (R2) obtained $78.2 \%$, these results indicate that the dependent variable (employee performance) can be explained by the independent variables (organizational culture, work stress, and job rotation), while the remaining $21.8 \%$ is influenced by variables in outside this research.
\end{abstract}

Keywords: Organizational Culture, Job Stress, Work Rotation, Employee Performance.

\begin{abstract}
Abstrak
Penelitian ini bertujuan untuk mengetahui apakah terdapat pengaruh budaya organisasi, stres kerja, dan rotasi kerja terhadap kinerja karyawan. Populasi dalam penelitian ini adalah seluruh karyawan Bank Panin KCU Kota Surakarta. Teknik pengambilan sampel menggunakan metode purposive sampling. Berdasarkan metode purposive sampling diperoleh sampel sebanyak 78 orang karyawan. Metode analisis data yang digunakan dalam penelitian ini adalah menggunakan analisis regresi linier berganda. Berdasarkan hasil pengujian simultan (uji F) menunjukkan bahwa variabel independen (budaya organisasi, stres kerja, dan rotasi kerja) berpengaruh positif dan signifikan terhadap variabel dependen (kinerja karyawan). Berdasarkan pengujian secara parsial (uji t) menunjukkan bahwa variabel budaya organisasi, stres kerja, dan rotasi kerja berpengaruh positif dan signifikan terhadap kinerja karyawan. Berdasarkan uji koefisien determinasi $\left(\mathrm{R}^{2}\right)$ diperoleh 78,2 \%, hasil ini menunjukkan bahwa variabel dependen (kinerja karyawan) dapat dijelaskan oleh variabel independen (budaya organisasi, stres kerja, dan rotasi kerja), sedangkan sisanya 21,8\% dipengaruhi oleh variabel di luar penelitian ini.
\end{abstract}

Kata Kunci : Budaya Organisasi, Stres Kerja, Rotasi Kerja, Kinerja Karyawan. 


\section{PENDAHULUAN}

Pada era globalisasi saat ini perusahaan yang berdiri di Indonesia sangatlah banyak, baik perusahaan yang kepemilikannya di miliki oleh orang Indonesia maupun oleh orang luar Indonesia (asing), oleh sebab itu persaingan antar perusahaan sangatlah ketat dalam berbagai bidang jenis industri yang ada di Indonesia ini. Dalam menghadapi persaingan tersebut perusahaan dituntut untuk mampu mengelola sumber daya manusia sebaik mungkin yaitu memperhatikan input dan output sumber daya manusia. Pengelolaan individu (sumber daya manusia) yang tepat seperti pelatihan, kesempatan, motivasi serta kesesuaian antara pendidikan dengan latar belakang mampu menghasilkan kinerja yang maksimal. Selain itu, antara atasan dengan bawahan harus menciptakan hubungan yang harmonis agar memperoleh lingkungan kerja yang kondusif serta nyaman bagi karyawan (Rahayu, 2018). Sumber daya manusia adalah faktor kunci dalam mencapai tujuan organisasi. Bentuk dan tujuan organisasi, berbagai visi dirancang untuk kepentingan manusia dimana dalam pelaksanaan misinya dikelola dan diurus oleh manusia. Ini berarti, bahwa manusia merupakan sumber daya strategis dalam semua aktivitas organisasi. Untuk itu, sumber daya manusia perlu direncanakan, dirumuskan strategi-strategi yang relevan dengan tujuan yang telah ditetapkan, serta konsisten dalam mengimplementasikannya secara kontinyu sehingga dapat meningkatnya kinerja (performance) organisasi dimana sumber daya manusia tersebut berada. Perencanaan strategis berkaitan dengan sumber daya manusia (SDM) yang dimaksudkan adalah perencanaan SDM yang harus memerhatikan faktor lain selain SDM (human) misalnya faktor keuangan (finance), sehingga dapat bersinergi dalam mencapai tujuan organisasi (Cahyana dan Jati, 2017).

Menurut Hastuti, (2018) kinerja (performance) merupakan suatu gambaran dari tingkat pencapaian pelaksanaan suatu kegiatan / program / kebijakan dalam mewujudkan sasaran, tujuan, visi dan misi organisasi yang tertuang dalam rencana strategi suatu organisasi. Keberhasilan kinerja dapat dilihat berdasarkan kriteria yang telah ditetapkan oleh individu maupun kelompok. Tolak ukur keberhasilan organisasi jasa keuangan dapat diketahui berdasarkan outcome yang mampu memenuhi harapan dan kebutuhan kebutuhan masyarakat.

Budaya organisasi merupakan nilai-nilai yang berkembang dalam suatu organisasi, di mana nilai-nilai tersebut digunakan untuk mengarahkan perilaku anggota-anggota organisasi. Perilaku pegawai tersebut dipengaruhi oleh lingkungan tempat mereka bekerja yang dibentuk melalui budaya organisasi, di mana keberadaan budaya dalam suatu organisasi diharapkan akan meningkatkan kinerja pegawai (Soedjono, 2005). Maka untuk mencapai profesional kerja, manajemen puncak dan divisi sumber daya manusia bisa menciptakan budaya kerja organisasi yang berkualitas.

Stres kerja adalah suatu faktor yang dialami oleh setiap individu dikarenakan adanya ketidakseimbangan antara tuntutan pekerjaan dengan kemampuan yang dimiliki oleh seseorang dalam menyelesaikan pekerjaanya. Seseorang harus dapat mengelola kondisi stres yang dialami supaya tidakberdampak negatif terhadap kinerja yang dihasilkan (Dewi, et.al, 2013). Selain dari faktor budaya organisasi, faktor lain yang turut berpengaruh terhadap peningkatan kepuasan kerja dan kinerja karyawan adalah masalah stres kerja yang dialami oleh karyawan karena adanya tuntutan pekerjaan dan tanggung jawab dari pimpinan dalam penyelesaian pekerjaan.

Menurut Kaymaz, (2010) rotasi kerja akan meningkatkan produktifitas pegawai yang berpengaruh terhadap kinerja karyawan. Oleh sebab itu, tidak jarang perusahaan menerapkan rotasi kerja untuk memaksimalkan kinerja dan mendorong agar karyawan tetap kreatif, rotasi kerja dilaksanakan dengan syarat tingkat kemampuan yang dimiliki sama. Dengan adanya rotasi kerja sebuah posisi atau jabatan tidak akan ditempati oleh seseorang dalam jangka waktu yang lama, sehingga karyawan tidak akan mengetahui 
secara terperinci peluang-peluang apa saja yang dapat menimbulkan ketidaksesuaian dalam pekerjaan.

\section{METODOLOGI}

\subsection{Populasi dan Sampling}

Pada penelitian ini populasi yang digunakan adalah seluruh karyawan yang bekerja di Bank Panin KCU Kota Surakarta. Populasi yang diambil dalam penelitian ini berjumlah 250 orang karyawan.

Teknik pengambilan sampel dalam penelitian ini menggunakan teknik purposive sampling dengan kriteria sebagai berikut :

a. Karyawan Bank Panin KCU Kota Surakarta.

b. Karyawan Bank Panin KCU Kota Surakarta yang telah bekerja selama minimal 3 tahun.

c. Karyawan Bank Panin KCU Kota Surakarta yang pernah mengalami rotasi pekerjaan.

Berdasarkan perhitungan diatas menggunakan teknik pengambilan sampel dengan purposive sampling diperoleh sampel penelitian sebesar 78 orang karyawan.

\subsection{Metode Analisis Data}

\subsubsection{Uji Instrumen}

\subsubsection{Uji Validitas}

Suatu kuesioner dikatakan valid jika pertanyaan pada kuesioner mampu untuk mengungkapkan sesuatu yang akan diukur oleh kuesioner tersebut (Ghozali, 2018). Uji validitas diukur menggunakan Pearson Correlation.

Adapun kriteria penilaian uji validitas adalah :

a) Apabila $r$ hitung $>r$ tabel, maka item kuisioner tersebut valid.

b) Apabila $\mathrm{r}$ hitung $<\mathrm{r}$ tabel, maka item kuisioner tersebut tidak valid.

\subsubsection{Uji Realibilitas}

Suatu kuesioner dikatakan reliabel atau handal jika jawaban seseorang terhadap pernyataan adalah konsisten atau stabil dari waktu ke waktu. Menurut Ghozali, (2018) menunjukkan bahwa Alpha cronbach's dapat diterima jika > 0,6. Semakin dekat alpha cronbach's dengan 1, semakin tinggi keandalan konsisten internal.

\subsubsection{Uji Asumsi Klasik}

\subsubsection{Uji Normalitas}

Ada dua cara untuk mendeteksi apakah residual berdistribusi normal atau tidak yaitu dengan analisis grafik dan analisis statistik (Ghozali, 2018). Pada penelitian untuk mengetahui normalitas menggunakan analisis grafik dan statistik. Uji statistik yang dapat digunakan untuk menguji normalitas residual adalah uji statistik nonparametik Kolgomorov-Smirnov (K-S) tingkat signifikansi $(\alpha)$ 0,05. Uji K-S dilakukan dengan membuat hipotesis (Ghozali, 2018) :

Ho : $\quad$ Data residual terdistribusi normal apabila Sig hitung $>0,05$

Ha : Data residual tidak terdistribusi normal apabila Sig hitung $<0,05$.

\subsubsection{Uji Multikolinearitas}

Model regresi yang baik semestinya tidak tidak terjadi korelasi diantara variabel independen. Cara mendeteksi ada tidaknya multikolinearitas yaitu dengan cara memperhatikan angka Variance Inflation Factor (VIF) dan tolerance. Nilai cutoff yang umum dipakai untuk menunjukkan adanya multikolinearitas adalah 
nilai tolerance lebih dari 0,10 atau sama dengan nilai VIF kurang dari 10 (Ghozali, 2018).

\subsubsection{Uji Heteroskedastisitas}

Model regresi yang baik adalah model regresi yang homoskedastisitas atau yang tidak terjadi heteroskedastisitas. Untuk menguji ada tidaknya heteroskedastisitas dapat dilakukan dengan melihat ada tidaknya pola tertentu pada grafik scatterplot antara SRESID (residual) dan ZPRED (variabel terikat) dimana sumbu $\mathrm{Y}$ adalah $\mathrm{Y}$ yang telah diprediksi, dan sumbu $\mathrm{X}$ adalah residual (Y prediksi - Y sesungguhnya) yang telah di studentized. Dasar analisisnya adalah sebagai berikut: (Ghozali, 2018)

1) Jika ada pola tertentu, seperti titik-titik yang ada membentuk pola tertentu yang teratur (bergelombang, melebar kemudian menyempit), maka mengindikasikan telah terjadi heteroskedastisitas

2) Jika tidak ada pola yang jelas, serta titik-titik menyebar di atas dan dibawah angka 0 pada sumbu y, maka tidak terjadi heteroskedastisitas.

\subsubsection{Uji Hipotesis}

\subsubsection{Analisis Regresi Linier Berganda}

Analisis regresi linier berganda bertujuan untuk mengetahui pengaruh variabel independen (budaya organisasi, stres kerja dan rotasi kerja) terhadap variabel dependen (kinerja karyawan). Persamaan regresi yang terbentuk adalah sebagai berikut :

$\mathrm{Y}=\alpha+\beta_{1} \mathrm{X}_{1}+\beta_{2} \mathrm{X}_{2}+\beta_{3} \mathrm{X}_{3}+\varepsilon$

Keterangan :

Y : Kinerja Karyawan

$\alpha \quad$ : Konstanta

$\beta \quad$ : Koefisien Regresi

$\mathrm{X}_{1} \quad$ : Budaya Organisasi

$\mathrm{X}_{2} \quad$ : Stres Kerja

$\mathrm{X}_{3} \quad$ : Rotasi Kerja

$\varepsilon \quad$ : Variabel Penggangu

\subsubsection{Uji Simultan (Uji F)}

Uji $F$ bertujuan untuk mengetahui pengaruh variabel independen (budaya organisasi, stres kerja, dan rotasi kerja) secara simultan terhadap variabel dependen (kinerja karyawan). Jika nilai $\mathrm{F}_{\text {hitung }}>\mathrm{F}_{\text {tabel }}$ dan nilai signifikansi $<0,05$, maka $\mathrm{H}_{0}$ ditolak artinya bahwa variabel independen secara simultan berpengaruh terhadap variabel dependen.

\subsubsection{Uji t}

Uji t bertujuan untuk mengetahui pengaruh variabel independen (budaya organisasi, stres kerja, dan rotasi kerja) secara parsial terhadap variabel dependen (kinerja karyawan). Pengujian dilakukan dengan menggunakan significance level 0,05 ( $\alpha=5 \%)$. apabila $t_{\text {hitung }}$ $>\mathrm{t}$ tabel atau dan $-\mathrm{t}$ hitung $<-\mathrm{t}$ tabel dan nilai signifikansi $<0,05$, maka dapat disimpulkan bahwa secara sendiri (parsial) variabel independen berpengaruh terhadap variabel dependen. 


\subsubsection{Uji Koefisien Determinasi $\left(\mathbf{R}^{2}\right)$}

Uji koefisien determinasi $\left(\mathrm{R}^{2}\right)$ digunakan untuk memprediksi seberapa besar kontribusi pengaruh variabel independen terhadap variabel dependen. Nilai koefisien determinasi adalah antara nol dan satu. Nilai yang mendekati satu berarti variabel-variabel independen memberikan hampir semua informasi yang dibutuhkan untuk memprediksi variasi variabel dependen.

\section{HASIL DAN PEMBAHASAN}

\subsection{Uji Instrumen}

\subsubsection{Uji Validitas}

Berdasarkan pengujian uji validitas, hasil pengujian disajikan dalam bentuk tabel berikut ini:

Tabel 1 : Hasil Uji Validitas

\begin{tabular}{cccc}
\hline Keterangan & $\mathrm{r}_{\text {hitung }}$ & $\mathrm{r}_{\text {tabel }}$ & Kesimpulan \\
\hline X1.1 & 0,481 & 0,223 & Valid \\
X1.2 & 0,635 & 0,223 & Valid \\
X1.3 & 0,542 & 0,223 & Valid \\
X1.4 & 0,682 & 0,223 & Valid \\
X1.5 & 0,667 & 0,223 & Valid \\
X2.1 & 0,683 & 0,223 & Valid \\
X2.2 & 0,710 & 0,223 & Valid \\
X2.3 & 0,611 & 0,223 & Valid \\
X2.4 & 0,773 & 0,223 & Valid \\
X2.5 & 0,698 & 0,223 & Valid \\
X3.1 & 0,681 & 0,223 & Valid \\
X3.2 & 0,640 & 0,223 & Valid \\
X3.3 & 0,694 & 0,223 & Valid \\
X3.4 & 0,705 & 0,223 & Valid \\
X3.5 & 0,492 & 0,223 & Valid \\
Y.1 & 0,778 & 0,223 & Valid \\
Y.2 & 0,743 & 0,223 & Valid \\
Y.3 & 0,758 & 0,223 & Valid \\
Y.4 & 0,755 & 0,223 & Valid \\
Y.5 & 0,640 & 0,223 & Valid
\end{tabular}

Sumber : data primer diolah.

Berdasarkan pada tabel 1 tersebut diatas dapat disimpulkan bahwa seluruh item pernyataan pada variabel Budaya Organisasi, Stres Kerja, Rotasi Kerja, dan Kinerja Karyawan sah / valid karena mempunyai nilai $\mathrm{r}_{\text {hitung }}$ yang lebih besar dari $\mathrm{r}_{\text {tabel }}\left(\mathrm{r}_{\text {hitung }}>\mathrm{r}_{\text {tabel }}\right)$ dan signifikansi $<0,05$.

\subsubsection{Uji Reliabilitas}

Berdasarkan pengujian uji reliabilitas, hasil pengujian disajikan dalam bentuk tabel berikut ini: 
Tabel 2 : Hasil Uji Reliabilitas

\begin{tabular}{ccc}
\hline Keterangan & Cronbach-Alpha & Kesimpulan \\
\hline Budaya Organisasi & 0,735 & Reliabel \\
Stres Kerja & 0,776 & Reliabel \\
Rotasi Kerja & 0,754 & Reliabel \\
\hline
\end{tabular}

Sumber : data primer diolah.

Berdasarkan pada tabel 2 tersebut diatas dapat disimpulkan bahwa seluruh item pernyataan yang berkaitan dengan variabel independen (budaya organisasi, stres kerja, dan rotasi kerja) dan variabel dependen (kinerja karyawan) dapat dikatakan reliabel, karena seluruh variabel mempunyai nilai cronbach's alpha $>0,60$.

\subsection{Uji Asumsi Klasik}

\subsubsection{Uji Normalitas}

Berdasarkan pengujian uji normalitas, hasil pengujian di sajikan dalam bentuk grafik dan tabel berikut ini :

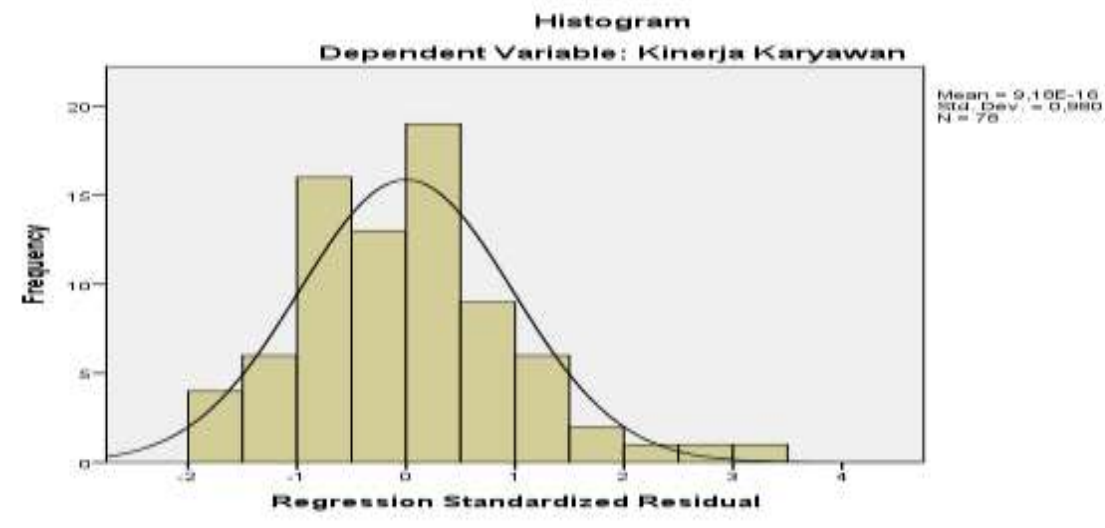

Gambar 1. Histogram Uji Normalitas

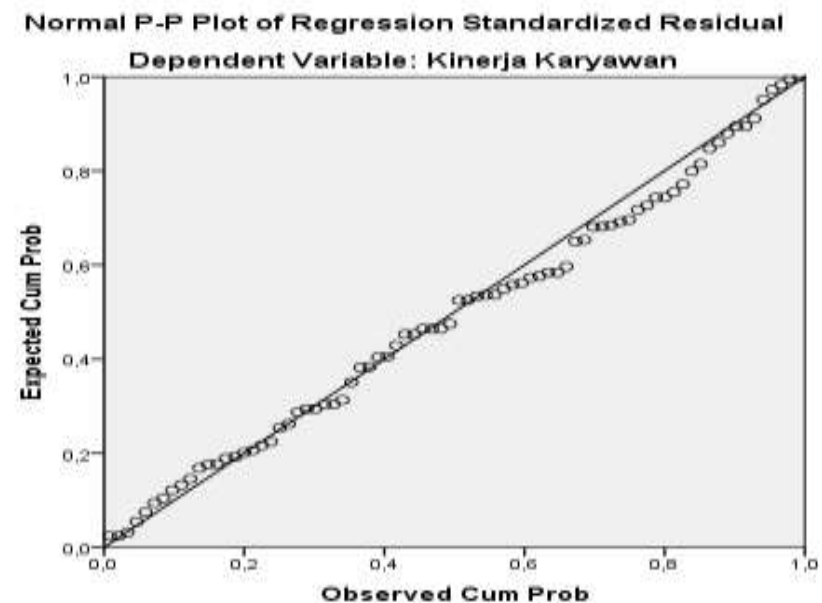

Gambar 2. Grafik Normal P-P Plot 
Tabel 3. Hasil Uji Normalitas

\begin{tabular}{cccc}
\hline Variabel & $\begin{array}{c}\text { Asymp-Sig } \\
(2 \text {-tailed })\end{array}$ & Standar & Keterangan \\
\hline $\begin{array}{c}\text { Unstandardized } \\
\text { Residual }\end{array}$ & 0,858 & $>0,05$ & Data terdistribusi normal \\
\hline
\end{tabular}

Sumber : data primer diolah.

Berdasarkan hasil uji normalitas pada tabel 2 diatas menunjukkan bahwa nilai pada gambar 1 dan 2 distribusi memusat pada daerah ditengah yang berarti bahwa distribusi data normal dan nilai P-P Plot mendekati garis diagonal, sehingga dapat dikatakan bahwa distribusi data adalah normal, sedangkan pada tabel 3 diatas nilai asymp-sig (2-tailed) dari unstandardized residual memiliki nilai > 0,05 yaitu 0,858. Hal ini dapat disimpulkan bahwa data terdisitribusi secara normal.

\subsubsection{Uji Multikolinearitas}

Berdasarkan pengujian uji multikolinearitas, hasil pengujian disajikan dalam tabel berikut ini :

Tabel 4. Hasil Uji Multikolinearitas

\begin{tabular}{lccc}
\hline \multicolumn{1}{c}{ Variabel } & Tolerance & VIF & Keterangan \\
\hline Budaya Organisasi & 0,505 & 1,978 & Tidak ada multikolinearitas \\
Stres Kerja & 0,389 & 2,571 & Tidak ada multikolinearitas \\
Rotasi Kerja & 0,300 & 3,335 & Tidak ada multikolinearitas \\
\hline
\end{tabular}

Sumber : data primer diolah.

Berdasarkan pada tabel 4 tersebut diatas dapat disimpulkan bahwa seluruh variabel tidak terdapat penyimpangan multikolinearitas, karena seluruh variabel memiliki nilai tolerance $>0,10$ dan nilai $\mathrm{VIF}<10$.

\subsubsection{Uji Heteroskedastisitas}

Berdasarkan pengujian uji heteroskedastisitas, hasil pengujian disajikan dalam gambar berikut ini:

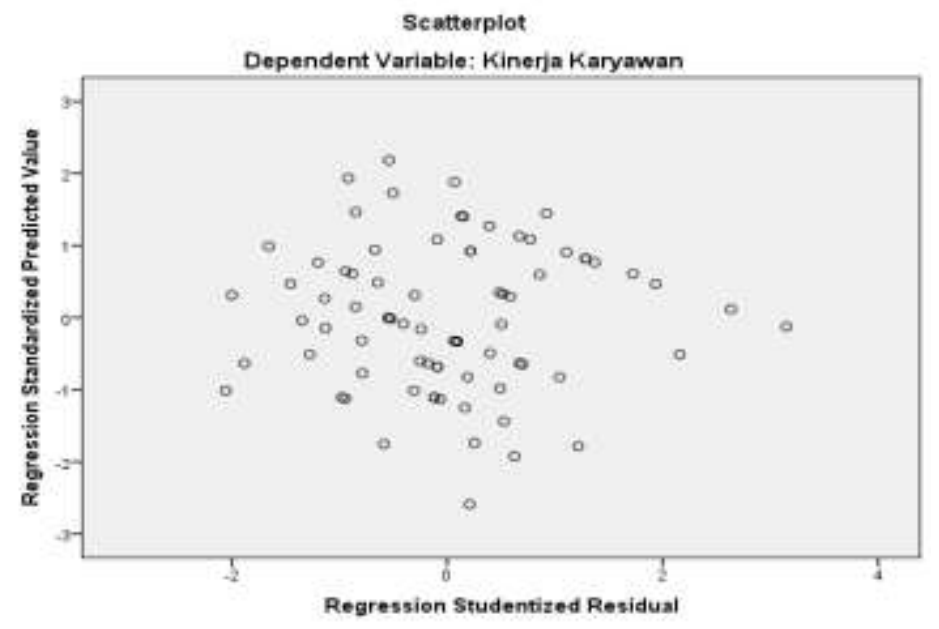

Gambar 3. Hasil Uji Heteroskedastisitas 
Berdasarkan pada gambar 3 tersebut diatas dapat disimpulkan bahwa titik-titik menyebar diatas dan dibawah angka 0 pada sumbu $Y$ dan membuat pola yang tidak teratur, hal ini dapat disimpulkan bahwa tidak terjadi heteroskedastisitas data penelitian.

\subsection{Uji Hipotesis}

\subsubsection{Analisis Regresi Linier Berganda}

Berdasarkan pengujian analisis regresi linier berganda, hasil pengujian disajikan dalam tabel berikut ini :

Tabel 5. Hasil Analisis Regresi Linier Berganda

\begin{tabular}{lc}
\multicolumn{1}{c}{ Variabel } & $\beta$ (Koefisien Regresi) \\
\hline Konstanta & $-0,791$ \\
Budaya Organisasi & 0,319 \\
Stres Kerja & 0,360 \\
Rotasi Kerja & 0,393 \\
\hline
\end{tabular}

Sumber : data primer diolah.

Berdasarkan hasil pengujian pada tabel IV.11 dengan menggunakan program SPSS, maka didapat persamaan regresi sebagai berikut :

$Y=-0,791+0,319 X_{1}+0,360 X_{2}+0,393 X_{3}$

Persamaan regresi yang terbentuk diatas memberikan pengertian sebagai berikut :

a. Konstanta yang diperoleh sebesar $-0,791$ menyatakan bahwa apabila semua variabel independen bernilai 0, maka kinerja karyawan akan sebesar $-0,791$.

b. Koefisien regresi variabel budaya organisasi bernilai positif sebesar 0,319 . Hal ini berarti apabila variabel budaya organisasi naik sebesar 1 persen dengan asumsi variabel yang lainnya tetap, maka akan diikuti dengan kenaikan pada kinerja karyawan sebesar 0,319.

c. Koefisien regresi variabel stres kerja bernilai positif sebesar 0,360. Hal ini berarti apabila variabel stres kerja naik sebesar 1 persen dengan asumsi variabel yang lainnya tetap, maka akan diikuti dengan kenaikan pada kinerja karyawan sebesar 0,360 .

d. Koefisien regresi variabel rotasi kerja bernilai positif sebesar 0,393. Hal ini berarti apabila variabel rotasi kerja naik sebesar 1 persen dengan asumsi variabel yang lainnya tetap, maka akan diikuti dengan kenaikan pada kinerja karyawan sebesar 0,393.

\subsubsection{Uji Simultan (Uji F)}

Berdasarkan pengujian uji $\mathrm{F}$, hasil pengujian disajikan dalam tabel berikut ini :

Tabel 6. Hasil Uji Simultan (Uji F)

\begin{tabular}{cccclc}
\hline Model & $F_{\text {hitung }}$ & $\mathrm{F}_{\text {tabel }}$ & Sig & Standar & Keterangan \\
\hline 1 & 93,324 & 2,73 & 0,000 & 0,05 & Model Layak \\
\hline
\end{tabular}

Sumber:data primer diolah.

Dari hasil perhitungan tersebut diperoleh $\mathrm{F}_{\text {hitung }}$ sebesar 93,324. Ternyata besarnya $F_{\text {hitung }}$ terletak didaerah penerimaan $\mathrm{H}_{\mathrm{a}}$ yaitu $\mathrm{F}_{\text {hitung }}>$ $F_{\text {tabel }}(93,324>2,73)$ dan nilai probabilitas signifikansi sebesar 0,033 yang artinya lebih kecil dari $0,05(0,000<0,05)$. Sehingga dapat 
disimpulkan bahwa secara bersama-sama atau simultan variabel independen (budaya organisasi, stres kerja, dan rotasi kerja) berpengaruh terhadap variabel dependen (kinerja karyawan). Hipotesis $1\left(\mathrm{H}_{1}\right)$ diterima.

\subsubsection{Uji t}

Berdasarkan pengujian uji t, hasil pengujian disajikan dalam tabel berikut ini :

Tabel. 7 Hasil Uji t

\begin{tabular}{lccccc}
\hline \multicolumn{1}{c}{ Variabel } & $\mathrm{t}_{\text {hitung }}$ & $\mathrm{t}_{\text {tabel }}$ & Sig. & Standar & Keputusan \\
\hline Budaya & 3,219 & 1,993 & 0,002 & $<0,05$ & H2 Diterima \\
Organisasi & & 1,993 & 0,000 & $<0,05$ & H3 Diterima \\
Stres Kerja & 4,434 & 1,993 & 0,000 & $<0,05$ & H4 Diterima \\
Rotasi Kerja & 3,839 &
\end{tabular}

Sumber: data primer diolah.

Hipotesis 2 nilai $t_{\text {hitung }}>t_{\text {tabel }}(3,219>1,993)$ dan signifikansi $<0,05$ $(0,002<0,05)$, maka Ho ditolak. Jadi dapat disimpulkan bahwa budaya organisasi berpengaruh positif dan signifikan terhadap kinerja karyawan. Hipotesis 2 nilai $t_{\text {hitung }}>t_{\text {tabel }}(4,434>1,993)$ dan signifikansi $<0,05(0,000$ $<$ 0,05), maka Ho ditolak. Jadi dapat disimpulkan bahwa stres kerja berpengaruh positif dan signifikan terhadap kinerja karyawan. Hipotesis 3 nilai thitung $>t_{\text {tabel }}(3,839>1,993)$ dan signifikansi $<0,05(0,000<0,05)$, maka Ho ditolak. Jadi dapat disimpulkan bahwa rotasi kerja berpengaruh positif dan signifikan terhadap kinerja karyawan.

\subsubsection{Uji Koefisien Determinasi $\left(\mathbf{R}^{2}\right)$}

Berdasarkan pengujian uji koefisien determinasi $\left(\mathrm{R}^{2}\right)$, hasil pengujian disajikan dalam tabel berikut ini :

Tabel.8 Hasil Uji Koefisien Determinasi $\left(\mathbf{R}^{2}\right)$

\begin{tabular}{ccc}
\hline Model & Adjusted $R$ Square & Kesimpulan \\
\hline 1 & 0,180 & Variabel independen dapat menjelaskan \\
variabel dependen
\end{tabular}

Sumber : data primer diolah.

Berdasarkan hasil perhitungan koefisien determinasi pada tabel 8 dapat diketahui bahwa variabel dependen dalam hal ini kepuasan pelanggan dapat dijelaskan sebesar 78,2 \% oleh variabel independen (budaya organisasi, stres kerja, dan rotasi kerja). Hal itu terlihat dari nilai Adjusted $R$ Square sebesar 0,782. Sedangkan sebesar 21,8 \% variabel dependen kinerja karyawan dipengaruhi oleh variabel-variabel lain yang tidak digunakan dalam penelitian ini.

\section{KESIMPULAN DAN SARAN} berikut:

Berdasarkan hasil analisis dan pembahasan, maka dapat disimpulkan sebagai

a. Hasil uji F menunjukan ada pengaruh simultan dan signifikan budaya organisasi, stres kerja, dan rotasi kerja terhadap kinerja karyawan Bank Panin KCU Solo.

b. Hasil uji t menunjukan bahwa: 
1) Ada pengaruh positif dan signifikan budaya organisasi terhadap kinerja karyawan Bank Panin KCU Solo.

2) Ada pengaruh positif dan signifikan stres kerja terhadap kinerja karyawan Bank Panin KCU Solo.

3) Ada pengaruh positif dan signifikan rotasi kerja terhadap kinerja karyawan Bank Panin KCU Solo.

c. Nilai koefisien determinasi $\left(\mathrm{R}^{2}\right)$ sebesar 0,782 atau $78,2 \%$ artinya variabel budaya organisasi, stres kerja, dan rotasi kerja memiliki pengaruh sebesar 78,2 \% terhadap kinerja karyawan sisanya sebesar 21,8 \% dipengaruhi oleh variabel diluar penelitian.

\section{DAFTAR PUSTAKA}

Anoraga, P. 2008. Psikologi Kerja. Jakarta : Rineka Cipta.

Cahyana, I. G. S dan Jati, I. K. 2017. Pengaruh Budaya Organisasi, Stres Kerja, Dan Kepuasan Kerja Terhadap Kinerja Pegawai. E-Jurnal Akuntansi Universitas Udayana Vol. 18, No. 2, Hal. 1314-1342.

Dewi, et.al. 2013. Pengaruh Stres Kerja Dan Kepuasan Kerja Terhadap Kinerja Karyawan Pada Bagian Tenaga Penjualan UD Surya Raditya Negara. Jurnal Manajemen Volume 2.

Ghozali, I. 2018. Aplikasi Analisis Multivariate dengan Program IBM SPSS 25. Badan Penerbit Universitas Diponegoro: Semarang.

Hastuti, T., 2018. Pengaruh Budaya Organisasi, Stres Kerja, Motivasi Dan Kepuasan Kerja Terhadap Kinerja Pegawai (Studi Empiris Pada Dinas Lingkungan Hidup Kabupaten Boyolali. Naskah Publikasi Universitas Muhammadiyah Surakarta.

Kaymaz, K. 2010. The Effect of Job Rotation Practices on Motivation : A Research On Managers In The Automotive Organizations. Business And Economics Research Journal. Vol 1, No. 3, Hal.69-85.

Mangkunegara, A. P. 2010. Evaluasi Kinerja SDM. Bandung : PT. Refika Aditama.

Moeheriono. 2012. Pengukuran Kinerja Berbasis Kompetensi. Jakarta: Raja Grafindo Persada.

Rahayu, N. I. 2018. Pengaruh Rotasi Kerja Dan Kompensasi Terhadap Kinerja Karyawan Dengan Kepuasan Kerja Sebagai Variabel Intervening Pada Kantor Bea dan Cukai Tipe Madya Pabean B Yogyakarta. Skripsi. Universitas Negeri Yogyakarta.

Robbins, S. P. 2008. Perilaku Organisasi, Jilid I dan II, Alih Bahasa : Hadyana Pujaatmaja. Jakarta: Prenhallindo.

Robbins, S. P dan Judge. 2008. Perilaku Organisasi Buku II. Jakarta: Salemba Empat. 
Windy Helena, Sudarwati, Istiqomah/ Edunomika Vol. 04, No. 02, 2020

Soedjono. 2005. Pengaruh Budaya Organisasi terhadap Kinerja Organisasi Dan Kepuasan Kerja Karyawan Pada Terminal Penumpang Umum di Surabaya. Jurnal Manajemen dan Kewirausahaan Vol. 7 No. 1. STIESIA Surabaya.

Yuniarsih, et.al. 2008. Manajemen Sumber Daya Manusia. Bandung : Alfabeta. 